\title{
Innate immunity in the lung: how epithelial cells fight against respiratory pathogens
}

\author{
R. Bals*, P.S. Hiemstra ${ }^{\#}$
}

Innate immunity in the lung: how epithelial cells fight against respiratory pathogens. R. Bals, P.S. Hiemstra. (C) ERS Journals Ltd 2004.

ABSTRACT: The human lung is exposed to a large number of airborne pathogens as a result of the daily inhalation of $\mathbf{1 0 , 0 0 0}$ litres of air. The observation that respiratory infections are nevertheless rare is testimony to the presence of an efficient host defence system at the mucosal surface of the lung.

The airway epithelium is strategically positioned at the interface with the environment, and thus plays a key role in this host defence system. Recognition systems employed by airway epithelial cells to respond to microbial exposure include the action of the toll-like receptors.

The airway epithelium responds to such exposure by increasing its production of mediators such as cytokines, chemokines and antimicrobial peptides. Recent findings indicate the importance of these peptides as effector molecules of innate immunity by killing microorganisms, but also as regulators of inflammation, immunity and wound repair. Finally, the clinical relevance of the functions of the airway epithelium in innate immunity is discussed.

Eur Respir J 2004; 23: 327-333.
*Dept of Internal Medicine, Division of Pulmonary Medicine, Hospital of the University of Marburg, Philipps-University,

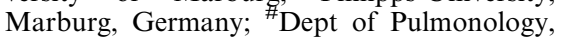
Leiden University Medical Center, Leiden, The Netherlands.

Correspondence: P.S. Hiemstra, Dept of Pulmonology, Leiden University Medical Center, P.O. Box 9600, 2300 RC Leiden, The Netherlands.

Fax: 31715266927

E-mail: p.s.hiemstra@lumc.nl

Keywords: Innate immunity, defensins, cathelicidins, infections, epithelium, antimicrobial peptide

Received: August 292003

Accepted: October 162003

The studies were supported by grants from: Deutsche Forschungsgemeinschaft the Bundesministerium für Bildung und Forschung, and the Cystic fibrosis foundation, Dutch Asthma foundation and Netherlands Organization for Scientific Research and the European Respiratory Society.
The integrity of the respiratory tract critically depends on a tightly regulated host defence apparatus. The innate immune system provides initial protection against microorganisms and stimulates the adaptive immune response [1]. Cellular components of the innate immune system include phagocytes such as neutrophils or macrophages, natural killer cells, basophils, mast cells, eosinophils and others. Epithelia of the human body form interfaces between the internal milieu and the external environment. In the respiratory tract, the epithelial lining the airways is the first point of contact for inhaled substances such as environmental pollutants, cigarette smoke, airborne allergens, and microorganisms [2]. In recent years it has become clear that airway epithelial cells not only provide a passive barrier function, but also actively contribute to the innate immune system $[2,3]$.

The innate immune functions of airway epithelial cells are of significance for the pathogenesis of a variety of human diseases. Failure of the local host defence apparatus may result in microbial colonisation and subsequently infection of the airways and the lung parenchyma. Mechanisms of the basal immunity provided by airway epithelial cells have a critical role in these settings. Activities of the innate immune system are closely linked to inflammatory processes. All major diseases of the lung involve mechanisms of the innate or adaptive immune system. Asthma and chronic obstructive lung disease (COPD) are chronic inflammatory diseases, in which cytokines and other mediators secreted from the airway epithelium are likely to play a critical role [3]. The role of antimicrobial peptides, small endogenous antibiotics with proinflammatory, and other functions, is less clear.

The aim of this review is to highlight the role of the airway epithelium in host defence and to describe new developments in this rapidly evolving area of research. Both the recognition systems used by airway epithelial cells to 'sense the microbial world' and the effector molecules produced in basal conditions and in response to microbial exposure are described. The focus in this latter part is on antimicrobial peptides. Whereas this review is mainly devoted to airway epithelial cells, also research on other epithelia (mainly those of the skin and the intestine) that is relevant to pulmonary research is discussed. Important input to the content of this review came from the European Respiratory Society research seminar "Host defence function of the airway epithelium" that was held in Noordwijkerhout, The Netherlands, 7-8 November, 2002.

\section{Recognition of pathogens by airway epithelial cells}

The airway epithelium senses bacterial exposure and responds accordingly by increasing its defences. This response consists of an increase in the release of e.g. antimicrobial 
peptides into the lumen of the airways, and the release of chemokines and cytokines into the submucosa that initiate an inflammatory reaction. This inflammatory reaction includes the recruitment of phagocytes, that serve to remove microorganisms that are not cleared by the epithelium itself, and dendritic cells and lymphocytes that may aid to mount an adaptive immune response.

Mechanisms to recognise pathogens by the airway epithelium are therefore considered essential to mount a protective response of the innate immune system. It has been known for a long time that cells can respond to microbial products such as lipopolysaccharide and lipoteichoic acid. However, the exact mechanisms and molecules involved in this response were incompletely understood. In the last decade much has been learnt about the mechanisms that mediate this 'adaptive' arm of the innate immune system. Cells of the innate immune system, including phagocytes, dendritic cells and epithelial cells, use so-called pattern recognition molecules to bind to conserved molecular patterns that are present on microorganisms. Pattern-recognition molecules can be present in secretions and the circulation in soluble form, such as mannan-binding lectin (MBL), or they can be transmembrane molecules that mediate direct cellular responses to microbial exposure. The toll-like receptors (TLR) constitute an intensely studied family of pattern recognition receptors $(10$ members of the human family have been recognised to date) that are represented by various members in almost all cells of the body. Their expression has been intensely studied on dendritic cells, and it is now recognised that these, TLRs, help to shape the adaptive immune response by directing the way that dendritic cells instruct T-cells. Airway epithelial cells also express a variety of TLRs that may help them to mount an adequate response to microbial exposure. Activation of TLR on epithelial cells has now been shown to be involved in the regulation of expression of a variety of genes, including those encoding cytokines, chemokines and antimicrobial peptides.

Following the identification of toll receptors in Drosophila flies as receptors involved in the fly's response to microbial exposure [4], the search for mammalian homologs led to the discovery of TLR in mammals. A variety of bacterial, fungal and viral products have now been identified as ligands for various TLRs and other pattern recognition receptors expressed by airway epithelial cells (summarised in table 1). Among the members of the TLR family, TLR 4 has been most intensively studied and its role in the response to lipopolysaccharide (LPS) has been subject of a large number of studies. Studies in LPS-hyporesponsive mice were essential in delineating the role of TLR4 in the response to LPS, and demonstrated that LPS-hyporesponsiveness in mice is associated with a mutation in the signalling domain of TLR4 [9-11]. Subsequent studies in humans revealed an association of selected polymorphisms in the human TLR4 gene with a variety of diseases, including Gram-negative bacterial infections in patients in an intensive care unit [12]. TLR4 is a central component in the response of cells to LPS. LPS is bound by LPS-binding protein (LBP), an acute phase protein that is produced not only by liver cells but also by epithelial cells in the lung [13]. LBP serves to transfer LPS to CD14, a molecule that together with the extracellular protein MD-2 is part of the TLR4 complex. This complex is involved in recognition of LPS, and this is followed by activation of a signalling complex that is associated with the intracellular domain of TLR4 and that includes the adaptor molecule MyD88 and related adaptors [5, 14] (discussed in more detail elsewhere in this section).

TLR2 recognises a wide array of microbial products from gram-positive and negative bacteria and from fungi. Like TLR4 it is present on airway epithelial cells. Whereas TLR4 appears to be the principle receptor for LPS, TLR2 also
Table 1.-Pattern recognition receptors involved in the recognition of microorganisms by airway epithelial cells

\begin{tabular}{|c|c|}
\hline Receptor & Ligand \\
\hline TLR1 & Tri-acyllipopeptides \\
\hline TLR2 & $\begin{array}{l}\text { Lipoteichoic acid, peptidoglycan, zymosan, } \\
\text { microbial lipoproteins and lipopeptides, } \\
\text { HSP70 (host) }\end{array}$ \\
\hline TLR3 & double-stranded RNA \\
\hline TLR4 & $\begin{array}{l}\text { LPS, HSP60 and } 70 \text { (host), hyaluronic acid } \\
\text { fragments (host) }\end{array}$ \\
\hline TLR5 & flagellin \\
\hline TLR6 & di-acyl lipopeptides \\
\hline TLR7 & synthetic compounds \\
\hline \multicolumn{2}{|l|}{ TLR8 } \\
\hline TLR9 & CpG DNA \\
\hline \multicolumn{2}{|l|}{ TLR10 } \\
\hline CD14 & LPS \\
\hline CFTR & LPS \\
\hline
\end{tabular}

TLR: Toll-like receptor; HSP: heat shock protein; $\mathrm{CpG}$ : bacterial deoxyribonucleic acid (DNA) containing unmethylated $\mathrm{CpG}$ dinulceotides; LPS; lipopolysaccharide; CFTR: cystic fibrosis transmembrane conductance regulator; Refer to text and references 5-8; TLR10 expression: R. Bals, unpublished observation.

detects certain structural variants of LPS such as leptospiral LPS [15]. The function of TLR3 was revealed by studies of TLR3 knockout mice, showing that TLR3 is essential in the response to double stranded (ds) ribonucleic acid (RNA) that is produced during viral infections [16]. TLR3 has been implicated in the response of epithelial cells to e.g. rhinovirus, rhinovirus dsRNA and synthetic dsRNA (polyinosinicpolycytidylic acid; poly(I;C)). This response consists of an increased expression not only of chemokines [6,17], but also of the human $\beta$-defensins (hBD)-2 and -3 [6]. TLR9 mediates the response to bacterial deoxyribonucleic acid (DNA). A recent study showed that TLR9 mediates the response of colonic epithelial cell lines to bacterial DNA, resulting in expression of interleukin (IL)-8 [18].

It is important to note that TLRs may also mediate the response to endogenous ligands. These ligands include heatshock proteins and extracellular matrix components, such as fragments of hyaluronic acid that are generated during inflammation. Also effector molecules of the innate immune system may serve as ligands for TLRs. The collectin surfactant protein A (SP-A) employs TLR4 to activate murine macrophages [19]. Mouse $\beta$-defensin-2 is another example of an effector molecule of innate immunity that activates cells via TLRs. This antimicrobial peptide was found to activate dendritic cells via TLR4, resulting in an increase in costimulatory molecules and dendritic cell maturation [20]. Whether this is the result of a classical receptor-ligand interaction remains to be determined [21].

Activation of TLRs may be involved in the regulation of a variety of genes involved in host defence, of which the cytokines and chemokines have been best characterised. It is now clear that TLR also regulate the expression of antimicrobial peptides. CD14, a part of the TLR4 receptor complex, was found to be essential in the LPS-induced induction of hBD-2 on tracheobronchial epithelial cells [7]. Subsequently, TLR2 was found to regulate the expression of $\mathrm{hBD}-2$ in response to bacterial lipoprotein in A549 lung epithelial cells [22], and hBD-2 and IL-8, in response to peptidoglycan and yeast cell wall particles in human keratinocytes [23]. TLR activation may also result in an increase in the expression of TLR themselves, which are normally not present in large amounts on epithelial cells. This is illustrated by the finding that nontypeable Haemophilus influenzae 
employs TLR2 to increase its expression on bronchial epithelial cells [24]. In addition, cytokines such as interferon (INF)- $\gamma$ have been found to increase the epithelial expression of selected TLRs [25].

A specific response to microbial products appears to result, in part, from individual TLRs possibly having their own signalling pathways, resulting in specific responses. Since different cell types express distinct subsets of TLRs, the simultaneous activation of different TLRs creates a unique signal to the cells that is characteristic, both for the cell type and the micro-organism involved [5, 14]. Recent studies have partly elucidated the intracellular signalling pathways activated by TLRs following binding of TLR-ligands. The common toll-interleukin-1 receptor (TIR)-domain of TLRs plays a central role in signalling. TLRs and IL-1R will bind the adaptor molecule MyD88 through the TIR-domain that is also present in MyD88. MyD88 recruits the serine/threonine kinase IL-1R-associated kinase (IRAK) that becomes phosphorylated, allowing it to associate with TRAF6. TRAF6 will mediate signalling to downstream molecules such mitogen activated protein kinases and transcription factors such as nuclear factor $\kappa \mathrm{B}$. Recent studies have also demonstrated the existence of MyD88-independent TLR signalling pathways. This led to the discovery of four other adaptor molecules in addition to MyD88: MyD88 adaptor-like (Mal; also known as Tir domain-containing adaptor protein [TIRAP]); TIRdomain containing adaptor inducing IFN- $\beta$ (TRIF; also known as TIR-containing adaptor molecule-1 [TICAM-1]), Trif-related adaptor molecule (TRAM) and sterile $\alpha$ - and HEAT-Armadillo motifs [26]. Whereas these adaptors, like MyD88, contain a TIR domain, they also show marked structural difference with MyD88. These may allow them to recruit different transducers resulting in specific down-stream signalling. Although the specific function of all these newly recognised adaptors remains to be fully clarified, the obvious advantage of the use of different adaptors by TLRs is to provide response specificity. Because components from different pathogens will engage different TLRs, an optimal response can be generated that results in elimination of a specific pathogen. In addition, it is tempting to speculate that these adaptor molecules may be future therapeutic targets in e.g. sepsis therapy aimed to block pro-inflammatory cascades initiated through TLRs while maintaining TLR-mediated protective responses [27]. However, whether blocking adaptors that mediate pro-inflammatory responses is compatible with effective clearance of microorganisms, and whether selective inhibitors of the different adaptors can be generated, is not clear.

\section{Antimicrobial peptides and proteins produced by airway epithelial cells}

Airway epithelial cells secrete a large array of molecules that are involved in inflammatory and immune processes [2, 3, 28]. This variety of substances produced by airway epithelial cells are summarised in figure 1. By secreting these mediators, the airway epithelium is capable to chemoattract and activate cells of the innate and adaptive immune system, to immobilise and kill microorganisms, to induce wound healing and angiogenesis in response to injury and to orchestrate the initiation of an adaptive immune response. Some of the secreted products have direct antimicrobial activity and likely act as endogenous antibiotics (fig. 1). These molecules include small cationic antimicrobial peptides such as the $\beta$-defensins and LL-37, but also larger antimicrobial proteins such as lysozyme, lactoferrin and secretory leukocyte proteinase inhibitor (SLPI; 29, 30). These molecules display microbicidal

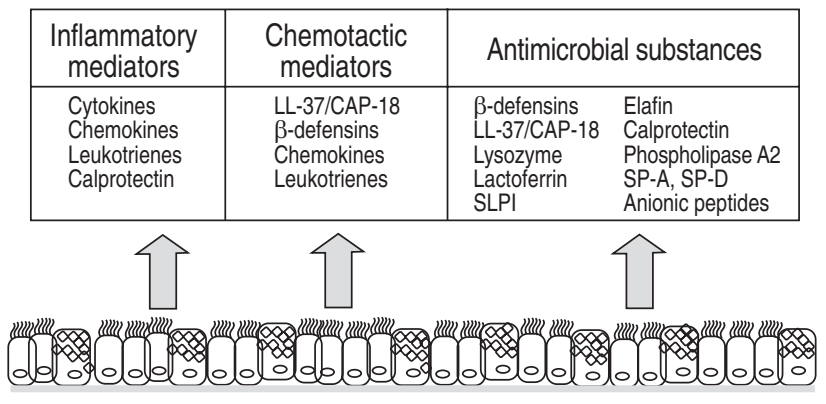

Fig. 1.-The role of the airway epithelium in host's defence against infection. Overview of secreted molecules that play a role in inflammation and host defence. Some of the depicted molecules appear to be secreted primary to the basolateral side (chemokines), whereas others are secreted to the apical side (antimicrobial peptides) of the epithelium.

activity or inhibit growth of inhaled microorganisms until they are eliminated by the mucociliary apparatus, recruited phagocytes and/or the development of an adaptive immune response.

Antimicrobial peptides are effector molecules of the innate immune system of the lung. Recently it was recognised that they have multiple additional activities besides their antimicrobial function. The term antimicrobial peptide refers to ribosomally synthesised, gene-encoded peptides, meaning that one gene in the genome codes for one peptide. Different groups of antimicrobial peptides are defined, based on structural characteristics. The defensins and cathelicidins are the principal families that are expressed in the respiratory tract. The primary translational product is a prepropeptide consisting of an N-terminal signal sequence for targeting to the endoplasmic reticulum, a pro segment, and a C-terminal cationic peptide that has antimicrobial activity after cleavage. The pro-peptide is cleaved during later stages of intracellular processing or after secretion.

Antimicrobial peptides in the human lung are mainly produced and secreted by epithelial and phagocytic cells. The expression and secretion of antimicrobial peptide genes is tightly regulated. Some peptides are produced constitutively, such as hBD-1 or mouse $\beta$-defensin 1 (mBD-1). The expression of others is increased by contact of cells with microbial products or proinflammatory mediators. It has been shown that expression of hBD-2, hBD-3, hBD-4, LL-37 and several other antimicrobial peptides is induced in vitro by bacterial products and inflammatory mediators [31-36]. These cell culture studies are confirmed by several patient studies, showing that the concentration of antimicrobial peptides such as $\beta$-defensins is increased in various body fluids during inflammatory or infectious diseases, such as pneumonia [37] or cystic fibrosis (38; summarised in table 2). From studies in keratinocytes it is known that the epithelial response to LPS is greatly enhanced by macrophages through the production of IL-1 [50] and similar mechanisms may operate to activate hBD-2 expression in pulmonary epithelial cells [51]. This may be an important mechanism for the amplification of the response to microbial products, since epithelial cells are markedly less sensitive to products such as LPS when compared to mononuclear phagocytes. Mechanisms involved in the epithelial regulation of human $\beta$-defensin expression by microbial products involves LPS detection by CD14 [7] and or lipoprotein recognition by toll-like receptor-2 [22]. Furthermore, growth factors involved in wound healing were found to increase expression of hBD-3, human cationic antimicrobial protein-18 (hCAP-18)/LL-37 and SLPI in human keratinocytes [52]. Regulation of LL-37 expression 
Table 2.-Presence of antimicrobial peptides produced by airway epithelial cells and airway host defence cells in human lung disease

\begin{tabular}{|c|c|c|}
\hline Component & Source & $\begin{array}{l}\text { Increased levels in } \\
\text { lung disease (references) }\end{array}$ \\
\hline \multirow[t]{6}{*}{$\alpha$-defensins } & Epithelial cells & Pneumonia $(39,40)$ \\
\hline & $\begin{array}{l}\text { Inflammatory } \\
\text { cells }\end{array}$ & Cystic fibrosis (41) \\
\hline & & Panbronchiololitis (42) \\
\hline & & ARDS (43) \\
\hline & & Chronic bronchitis (44) \\
\hline & & $\begin{array}{l}\text { Idiopathic pulmonary } \\
\text { fibrosis }(45)\end{array}$ \\
\hline \multirow{2}{*}{$\begin{array}{l}\beta \text {-defensin (BD) } \\
\text { hBD-1 }\end{array}$} & Epithelial cells & Pneumonia $(37,46)$ \\
\hline & $\begin{array}{l}\text { Monocytes/ } \\
\text { macrophages }\end{array}$ & Cystic fibrosis $(38,47)$ \\
\hline hBD-2 & Dendritic clls & Panbronchiolitis (48) \\
\hline hBD-3 & & \\
\hline hBD-4 & & \\
\hline \multirow{2}{*}{$\begin{array}{l}\text { Cathelicidin } \\
\text { LL-37/hCAP-18 }\end{array}$} & Epithelial cells, & Pneumonia (46) \\
\hline & Neutrophils & Sarcoidosis (49) \\
\hline
\end{tabular}

ARDS: acute respiratory distress syndrome.

in epithelial cells depends furthermore on the differentiation status of the cells $[53,54]$.

Antimicrobial peptides have a broad spectrum activity against Gram-positive and Gram-negative bacteria as well as against fungi and enveloped viruses [55]. Antimicrobial peptides show synergistic activity with other host defence molecules, such as lysosyme and lactoferrin. The antimicrobial activity is based on interactions between the peptide and surface membranes of the target organisms. Functional studies on antimicrobial activity have primarily been restricted to in vitro experiments using purified components. Recently, several groups published results that provided proof of the host defence function of antimicrobial peptides in living organisms. Indirect in vivo evidence for the host defence function of antimicrobial peptides came from a study on mice with a disrupted gene for matrilysin, also called matrix metalloprotease 7. Matrilysin-deficient mice were more susceptible to infections with enteropathogens [56]. Mice deficient in an antimicrobial peptide, $\mathrm{mBD}-1$, revealed delayed clearance of Haemophilus influenzae from lung [57]. Mice with deleted cathelin-related antimicrobial protein-18, the murine homologue of LL-37, showed more prominent infection after cutaneous inoculation of bacteria [58]. Conversely, the overexpression of LL-37 by viral gene transfer resulted in augmentation of innate host defence in a bronchial xenograft model of cystic fibrosis and in murine animal models of pneumonia and septic shock [59, 60]. In addition, overexpression of a defensin in a transgenic murine model provided protection against enteric salmonellosis [61].

Several lines of evidence indicate the importance of antimicrobial peptides in the human lung. Using culture systems of airway epithelial cells from patients with cystic fibrosis, it was demonstrated that epithelial-cell derived antimicrobial peptides may be inactivated by the high salt concentration in the epithelial lining fluid $[62,63]$. Studies in a human bronchial xenograft model revealed decreased antimicrobial activity of airway surface fluid after inhibition of hBD-1 synthesis by antisense oligonucleotides [63]. Other evidence for the importance of antimicrobial peptides comes from studies such as those showing that their levels are changed in inflammatory lung disease (table 2; 64), and the finding that nasal Staphlococcus aureus carriage is associated with decreased antibacterial activity of nasal fluid [65]. Finally, also the observation that hBD-1 polymorphisms are associated with COPD suggests that these peptides are important in vivo [66].

Antimicrobial peptides have a variety of other biological effects besides their antimicrobial activity. Based on their membrane activity, antimicrobial peptides have a concentration-dependent toxicity towards eukaryotic cells. High concentrations of $\alpha$-defensins have been described in secretions of patients with cystic fibrosis [41] and chronic bronchitis [44], where these substances likely contribute to the overwhelming inflammation. This may in part be explained by the ability of $\alpha$-defensins to cause lysis of lung epithelial cells and induction of IL-8 production in these cells [67]. Furthermore, whereas binding of $\alpha$-defensins to proteinase inhibitors of the serpin family such as $\alpha_{1}$-antitrypsin $\left(\alpha_{1}\right.$-AT) may restrict defensininduced cytotoxicity, it also decreases the elastase-inhibitory activity of $\alpha_{1}$-AT [44].

Besides this rather nonspecific toxicity caused by high concentrations, antimicrobial peptides bind to cellular receptors at low concentrations and activate intracellular signalling pathways. $\alpha$-defensins are able to stimulate a variety of cells by mechanisms not yet identified. They attract human CD4/ CD45RA + or CD8+ T cells [68, 69], immature dendritic cells [69], and monocytes [70]. They also induce the release of IFN$\gamma$, IL-6, and IL-10 from T-cells [71]. hBD-1 and hBD-2 were found to bind to a chemokine receptor known as CCR-6 [72]. This receptor is found on immature dendritic and memory $\mathrm{T}$ cells (CD4+/CD45RO+) and consequently these findings are interpreted as a link between innate and adaptive immune mechanisms mediated by defensins. hBD-3 and hBD- 4 chemoattract monocytes by mechanisms that have not yet been clarified [36, 73]. Cathelicidins may display similar activities as defensins, since LL-37 binds to formyl peptide receptor like 1 [74] and attracts neutrophils, monocytes, and CD4 T cells and activates mast cells [75]. It is interesting to note that whereas antimicrobial peptides may act as chemokines, the reverse has also been observed since several intact or truncated forms of chemokines display antimicrobial activity [76]. In addition to these roles of defensins and LL-37 in inflammation and immunity, defensins and LL-37 have also been implicated in wound repair processes. Neutrophil $\alpha$-defensins were found to cause proliferation of airway epithelial cells and mediate epithelial wound repair [77], whereas $\beta$-defensins may promote differentiation of keratinocytes [78]. In line with this, LL-37 is involved in reepithelialisation of cutaneous wounds [79], and induces angiogenesis in vitro and in vivo [80].

Despite the progress that has been made in the understanding of the basic biology of antimicrobial peptides, their role in human disease is still incompletely understood. Based on their direct host defence and various receptor-mediated functions, antimicrobial peptides could have a central role in infectious and inflammatory diseases. Table 2 summarises disease conditions that are characterized by altered concentrations of antimicrobial peptides.

Antimicrobial peptides have emerged as effector substances of the innate immune system involving not only activities as endogenous antibiotics but also as mediators of inflammation. Further analysis of the biologically relevant functions of antimicrobial peptides will reveal the role that these molecules have in diseases of the lung. Here, antimicrobial peptides might contribute to the development of diseases not only as endogenous host defence substance but also as pro- or antiinflammatory mediators. Development of antimicrobial peptides as drugs involves optimized strategies for candidate identification, for modification of pharmacodynamic and pharmacokinetic profiles and for production. Studying the biology of antimicrobial peptides should allow the development of novel therapeutics for infectious or inflammatory diseases. 


\section{Conclusions}

It is evident that there is a renewed and increased interest in innate immunity that has intensified studies on the role of the airway epithelium that forms the primary interface between the environment and the host. The epithelium contributes to host defence in a number of ways, including ciliary beat activity and mucus production, but also production of chemokines, cytokines, antimicrobial peptides, proteinase inhibitors and surfactant proteins. The recognition systems used by epithelial cells to sense microbial exposure do have a certain degree of specificity, and serve to mount a quick and efficient response to deal with a certain pathogen. Studies to elucidate the role of these mechanisms in human lung disease are ongoing, and include genetic studies to identify the association between polymorphisms in genes of innate immunity and lung disease. Such studies have identified MBL, hBD-1 and TLR 4 as potential modifier genes in human disease such as cystic fibrosis and COPD.

Current studies are exploring the possibility to modulate the innate immune response of the epithelium to increase local defence or to employ the present knowledge of antimicrobial peptides to develop a new class of antibiotics. These are all promising developments in the application of our increased knowledge of the basic elements of the innate immune system to the development of new therapies for infectious and inflammatory lung disease. This is especially important in view of the emergence of microorganisms resistant to conventional antibiotics, which forms a threat to human health and constitutes an economic burden for health care.

\section{References}

1. Medzhitov R, Janeway CA Jr. Innate immunity: impact on the adaptive immune response. Curr Opin Immunol 1997; 9: 4-9.

2. Diamond G, Legarda D, Ryan LK. The innate immune response of the respiratory epithelium. Immunol Rev 2000; 173: 27-38.

3. Holgate ST, Lackie P, Wilson S, Roche W, Davies D. Bronchial epithelium as a key regulator of airway allergen sensitization and remodeling in asthma. Am J Respir Crit Care Med 2000; 162: S113-S117.

4. Lemaitre B, Reichhart JM, Hoffmann JA. Drosophila host defense: Differential induction of antimicrobial peptide genes after infection by various classes of microorganisms. Proc Natl Acad Sci Usa 1997; 94: 14614-14619.

5. Takeda K, Kaisho T, Akira S. Toll-like receptors. Annu Rev Immunol 2003; 21: 335-376.

6. Duits LA, Nibbering PH, van Strijen E, et al. Rhinovirus increases human [beta]-defensin-2 and -3 mRNA expression in cultured bronchial epithelial cells. FEMS Immunology and Medical Microbiology 2003; 38: 59-64.

7. Becker MN, Diamond G, Verghese MW, Randell SH. CD14-dependent lipopolysaccharide-induced beta-defensin2 expression in human tracheobronchial epithelium. $J$ Biol Chem 2000; 275: 29731-29736.

8. Jaumann F, Unterberger P, Villena H, Welsch U, Vogelmeier C, Bals R. Differential expression and regulation of Toll-like receptors $1-9$ in human airway epithelium. Am J Respir Crit Care Med 163, A379. 2001.

9. Poltorak A, He X, Smirnova I, et al. Defective LPS signaling in $\mathrm{C} 3 \mathrm{H} / \mathrm{HeJ}$ and $\mathrm{C} 57 \mathrm{BL} / 10 \mathrm{ScCr}$ mice: mutations in Tlr4 gene. Science 1998; 282: 2085-2088.

10. Qureshi ST, Lariviere L, Leveque G, et al. Endotoxintolerant mice have mutations in Toll-like receptor 4 (Tlr4). J Exp Med 1999; 189: 615-625.

11. Hoshino K, Takeuchi O, Kawai T, et al. Cutting Edge: Tolllike receptor 4 (TLR4)-deficient mice are hyporesponsive to lipopolysaccharide: evidence for TLR4 as the Lps gene product. J Immunol 1999; 162: 3749.

12. Agnese DM, Calvano JE, Hahm SJ, et al. Human toll-like receptor 4 mutations but not CD14 polymorphisms are associated with an increased risk of gram-negative infections. J Infect Dis 2002; 186: 1522-1525.

13. Dentener MA, Vreugdenhil ACE, Hoet PHM, et al. Production of the acute-phase protein lipopolysaccharidebinding protein by respiratory type II epithelial cells. Implications for local defense to bacterial endotoxins. $\mathrm{Am}$ J Respir Cell Mol Biol 2000; 23: 146.

14. Underhill DM, Ozinsky A. Toll-like receptors: key mediators of microbe detection. Curr Opin Immunol 2002; 14: 103-110.

15. Werts C, Tapping RI, Mathison JC, et al. Leptospiral lipopolysaccharide activates cells through a TLR2-dependent mechanism. Nat Immunol 2001; 2: 346-352.

16. Alexopoulou L, Holt AC, Medzhitov R, Flavell RA. Recognition of double-stranded RNA and activation of NF-kappaB by Toll- like receptor 3. Nature 2001; 413: 732738.

17. Gern JE, French DA, Grindle KA, et al. Double-stranded RNA induces the synthesis of specific chemokines by bronchial epithelial cells. Am J Respir Cell Mol Biol 2003; 28: 731 .

18. Akhtar M, Watson JL, Nazli A, McKay DM. Bacterial DNA evokes epithelial IL-8 production by a MAPKdependent, NFkappaB-independent pathway. FASEB J: 2003: 1319-1321.

19. Guillot L, Balloy V, McCormack FX, et al. Cutting edge: the immunostimulatory activity of the lung surfactant protein-A involves Toll-like receptor 4. J Immunol 2002; 168: 59895992.

20. Biragyn A, Ruffini PA, Leifer CA, et al. Toll-like receptor 4-dependent activation of dendritic cells by beta- defensin 2 . Science 2002; 298: 1025-1029.

21. Ganz T. Immunology: Versatile Defensins. Science 2002; 298: 977.

22. Birchler T, Seibl R, Buchner K, et al. Human Toll-like receptor 2 mediates induction of the antimicrobial peptide human beta-defensin 2 in response to bacterial lipoprotein. Eur J Immunol 2001; 31: 3131-3137.

23. Kawai K, Shimura H, Minagawa M, et al. Expression of functional Toll-like receptor 2 on human epidermal keratinocytes. J Dermatol Sci 2002; 30: 185-194.

24. Imasato A, Desbois-Mouthon C, Han J, et al. Inhibition of p38 MAPK by glucocorticoids via induction of MAPK phosphatase-1 enhances nontypeable Haemophilus influenzaeinduced expression of toll-like receptor 2. J Biol Chem 2002; 277: 47444-47450.

25. Wolfs TG, Buurman WA, Van Schadewijk A, et al. IFNgamma and TNF-alpha Mediated Up-Regulation During Inflammation. J Immunol 2002; 168: 1286-1293.

26. $\mathrm{O}^{\prime}$ Neill LAJ, Fitzgerald KA, Bowie AG. The Toll-IL-1 receptor adaptor family grows to five members. Trends in Immunology 2003; 24: 287-290.

27. Yeh WC, Chen NJ. Another toll road. Nature 2003; 424: $736-737$.

28. Davies DE. The bronchial epithelium in chronic and severe asthma. Curr Allergy Asthma Rep 2001; 1: 127-133.

29. Hiemstra PS. Epithelial antimicrobial peptides and proteins: their role in host defence and inflammation. Paediatr Respir Rev 2001; 2: 306-310.

30. Schutte BC, McCray PB Jr. [beta]-defensins in lung host defense. Annu Rev Physiol 2002; 64: 709-748.

31. Harder J, Meyer-Hoffert U, Teran LM, et al. Mucoid Pseudomonas aeruginosa, TNF-alpha, and IL-1beta, but not IL-6, induce human beta-defensin-2 in respiratory epithelia. Am J Respir Cell Mol Biol 2000; 22: 714-721.

32. $\mathrm{O}^{\prime}$ Neil DA, Porter EM, Elewaut D, et al. Expression and regulation of the human beta-defensins hBD-1 and hBD-2 in intestinal epithelium. J Immunol 1999; 163: 6718-6724.

33. Tsutsumi-Ishii Y, Nagaoka I. NF-kappa B-mediated 
transcriptional regulation of human beta-defensin-2 gene following lipopolysaccharide stimulation. J Leukoc Biol 2002; 71: 154-162.

34. Krisanaprakornkit S, Kimball JR, Dale BA. Regulation of human beta-defensin-2 in gingival epithelial cells: the involvement of mitogen-activated protein kinase pathways, but not the NF-kappaB transcription factor family. J Immunol 2002; 168: 316-324.

35. Takahashi A, Wada A, Ogushi K, et al. Production of betadefensin-2 by human colonic epithelial cells induced by Salmonella enteritidis flagella filament structural protein. FEBS Lett 2001; 508: $484-488$

36. Garcia JR, Jaumann F, Schulz S, et al. Identification of a novel, multifunctional beta-defensin (human beta- defensin 3) with specific antimicrobial activity. Its interaction with plasma membranes of Xenopus oocytes and the induction of macrophage chemoattraction. Cell Tissue Res 2001; 306: 257-264.

37. Hiratsuka T, Nakazato M, Date Y, et al. Identification of human beta-defensin-2 in respiratory tract and plasma and its increase in bacterial pneumonia. Biochem Biophys Res Commun 1998; 249: 943-947.

38. Bals R, Weiner DJ, Meegalla RL, Accurso F, Wilson JM. Salt-independent abnormality of antimicrobial activity in cystic fibrosis airway surface fluid. Am J Respir Cell Mol Biol 2001; 25: 21-25.

39. Ashitani J, Mukae H, Hiratsuka T, et al. Plasma and BAL Fluid Concentrations of Antimicrobial Peptides in Patients With Mycobacterium avium- intracellulare Infection. Chest 2001; 119: 1131-1137.

40. Ashitani J, Mukae H, Hiratsuka T, et al. Elevated Levels of \{alpha\}-Defensins in Plasma and BAL Fluid of Patients With Active Pulmonary Tuberculosis. Chest 2002; 121: 519526.

41. Soong LB, Ganz T, Ellison A, Caughey GH. Purification and characterization of defensins from cystic fibrosis sputum. Inflamm Res 1997; 46: 98-102.

42. Ashitani J, Mukae H, Nakazato M, et al. Elevated concentrations of defensins in bronchoalveolar lavage fluid in diffuse panbronchiolitis. Eur Respir J 1998; 11: 104 111.

43. Ihi T, Nakazato M, Mukae H, Matsukura S. Elevated concentrations of human neutrophil peptides in plasma, blood, and body fluids from patients with infections. Clin Infect Dis 1997; 25: 1134-1140.

44. Panyutich AV, Hiemstra PS, van Wetering S, Ganz T. Human neutrophil defensin and serpins form complexes and inactivate each other. Am J Respir Cell Mol Biol 1995; 12: 351-357.

45. Mukae $\mathrm{H}$, Iiboshi $\mathrm{H}$, Nakazato $\mathrm{M}$, et al. Raised plasma concentrations of \{alpha\}-defensins in patients with idiopathic pulmonary fibrosis. Thorax 2002; 57: 623-628.

46. Schaller-Bals S, Schulze A, Bals R. Increased Levels of Antimicrobial Peptides in Tracheal Aspirates of Newborn Infants during Infection. Am J Resp Crit Care Med 2002; 165: 992-995.

47. Singh PK, Jia HP, Wiles K, et al. Production of betadefensins by human airway epithelia. Proc Natl Acad Sci US A 1998; 95: 14961-14966.

48. Hiratsuka $\mathrm{T}$, Mukae $\mathrm{H}$, Iiboshi $\mathrm{H}$, et al. Increased concentrations of human $\{$ beta\}-defensins in plasma and bronchoalveolar lavage fluid of patients with diffuse panbronchiolitis. Thorax 2003; 58: 425-430.

49. Agerberth B, Grunewald J, Castanos-Velez E, et al. Antibacterial components in bronchoalveolar lavage fluid from healthy individuals and sarcoidosis patients. Am J Respir Crit Care Med 1999; 160: 283-290.

50. Liu L, Roberts AA, Ganz T. By IL-1 signaling, monocytederived cells dramatically enhance the epidermal antimicrobial response to lipopolysaccharide. J Immunol 2003; 170: $575-580$.

51. Tsutsumi-Ishii Y, Nagaoka I. Modulation of human beta-defensin-2 transcription in pulmonary epithelial cells by lipopolysaccharide-stimulated mononuclear phagocytes via proinflammatory cytokine production. $J$ Immunol 2003; 170: $4226-4236$.

52. Sorensen OE, Cowland JB, Theilgaard-Monch $\mathrm{K}$, et al. Wound healing and expression of antimicrobial peptides/ polypeptides in human keratinocytes, a consequence of common growth factors. J Immunol 2003; 170: 5583-5589.

53. Schauber J, Svanholm C, Termen S, et al. Expression of the cathelicidin LL-37 is modulated by short chain fatty acids in colonocytes: relevance of signalling pathways. Gut 2003; 52: 735-741.

54. Hase K, Eckmann L, Leopard JD, Varki N, Kagnoff MF. Cell differentiation is a key determinant of cathelicidin LL37/human cationic antimicrobial protein 18 expression by human colon epithelium. Infect Immun 2002; 70: 953-963.

55. Koczulla AR, Bals R. Antimicrobial peptides: current status and therapeutic potential. Drugs 2003; 63: 389-406.

56. Wilson CL, Ouellette AJ, Satchell DP, et al. Regulation of intestinal alpha-defensin activation by the metalloproteinase matrilysin in innate host defense. Science 1999; 286: 113-117.

57. Moser C, Weiner DJ, Lysenko E, et al. beta-Defensin 1 contributes to pulmonary innate immunity in mice. Infect Immun 2002; 70: 3068-3072.

58. Nizet V, Ohtake $\mathrm{T}$, Lauth $\mathrm{X}$, et al. Innate antimicrobial peptide protects the skin from invasive bacterial infection. Nature 2001; 414: 454457.

59. Bals R, Weiner DJ, Meegalla RL, Wilson JM. Transfer of a cathelicidin peptide antibiotic gene restores bacterial killing in a cystic fibrosis xenograft model. J Clin Invest 1999; 103: 1113-1117.

60. Bals R, Griese M. Kleinmolekulare antimikrobielle Substanzen der Atemwegsfluessigkeit. In: Reinhardt D, Goetz M, Kraemer R, Schoeni M, editors. Mukoviszidose. Heidelberg, Springer, 1999

61. Salzman NH, Ghosh D, Huttner KM, Paterson Y, Bevins CL. Protection against enteric salmonellosis in transgenic mice expressing a human intestinal defensin. Nature 2003; 422: 522-526.

62. Smith JJ, Travis SM, Greenberg EP, Welsh MJ. Cystic fibrosis airway epithelia fail to kill bacteria because of abnormal airway surface fluid. Cell 1996; 85: 229-236.

63. Goldman MJ, Anderson GM, Stolzenberg ED, et al. Human $\beta$-defensin- 1 is a salt-sensitive antibiotic in the lung that is inactivated in cystic fibrosis. Cell 1997; 88: 553-560.

64. Aarbiou J, Rabe KF, Hiemstra PS. Role of defensins in inflammatory lung disease. Ann Med 2002; 34: 96-101.

65. Cole AM, Tahk S, Oren A, et al. Determinants of Staphylococcus aureus nasal carriage. Clin Diagn Lab Immunol 2001; 8: 1064-1069.

66. Matsushita I, Hasegawa K, Nakata K, et al. Genetic variants of human beta-defensin-1 and chronic obstructive pulmonary disease. Biochem Biophys Res Commun 2002; 291: 1722.

67. van Wetering S, Mannesse-Lazeroms SPG, Van Sterkenburg MAJA, et al. Effect of defensins on IL-8 synthesis in airway epithelial cells. Am J Physiol (Lung Cell Mol Physiol) 1997; 272: L888-L896.

68. Chertov $\mathrm{O}$, Michiel $\mathrm{DF}, \mathrm{Xu} \mathrm{L}$, et al. Identification of defensin-1, defensin-2 and CAP37/azurocidin as T-cell chemoattractant proteins released from interleukin-8-stimulated neutrophils. J Biol Chem 1996; 271: 2935-2940.

69. Yang D, Chen Q, Chertov O, Oppenheim JJ. Human neutrophil defensins selectively chemoattract naive $\mathrm{T}$ and immature dendritic cells. J Leukoc Biol 2000; 68: 9-14.

70. Territo MC, Ganz T, Selsted ME, Lehrer R. Monocytechemotactic activity of defensins from human neutrophils. J Clin Invest 1989; 84: 2017-2020.

71. Lillard JW Jr, Boyaka PN, Chertov O, Oppenheim JJ, McGhee JR. Mechanisms for induction of acquired host immunity by neutrophil peptide defensins. Proc Natl Acad Sci U S A 1999; 96: 651-656. 
72. Yang D, Chertov O, Bykovskaia SN, et al. Beta-defensins: linking innate and adaptive immunity through dendritic and T cell CCR6. Science 1999; 286: 525-528.

73. Garcia J-RC, Krause A, Schulz S, et al. Human betadefensin 4: a novel inducible peptide with a specific saltsensitive spectrum of antimicrobial activity. FASEB J 2001; 15: 1819-1821.

74. Yang D, Chen Q, Schmidt AP, et al. LL-37, the neutrophil granule- and epithelial cell-derived cathelicidin, utlizes formyl peptide receptor-like 1 (FPRL1) as a receptor to chemoattract human peripheral blood neutrophils, monocytes, and T cells. JEM 2000; 192: 1069-1074.

75. Niyonsaba F, Someya A, Hirata M, Ogawa H, Nagaoka I. Evaluation of the effects of peptide antibiotics human betadefensins- 1/-2 and LL-37 on histamine release and prostaglandin $\mathrm{D}(2)$ production from mast cells. Eur J Immunol 2001; 31: 1066-1075.
76. Durr M, Peschel A. Chemokines meet defensins: the merging concepts of chemoattractants and antimicrobial peptides in host defense. Infect Immun 2002; 70: 6515-6517.

77. Aarbiou J, Verhoosel RM, van Wetering S, et al. Neutrophil defensins enhance lung epithelial wound closure and mucin gene expression in vitro. Am J Resp Cell Mol Biol 2004; (in press).

78. Frye M, Bargon J, Gropp R. Expression of human betadefensin-1 promotes differentiation of keratinocytes. $J \mathrm{Mol}$ Med 2001; 79: 275-282.

79. Heilborn JD, Nilsson MF, Kratz G, et al. The cathelicidin anti-microbial peptide LL-37 is involved in re- epithelialization of human skin wounds and is lacking in chronic ulcer epithelium. J Invest Dermatol 2003; 120: 379-389.

80. Koczulla R, von Degenfeld G, Kupatt C, et al. An angiogenic role for the human peptide antibiotic LL-37/ hCAP-18. J Clin Invest 2003; 111: 1665-1672. 